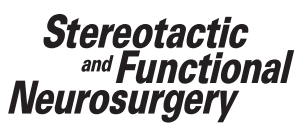

Stereotactic

Neurosurgery
Stereotact Funct Neurosurg 2010;88:199-207

DOI: $\underline{10.1159 / 000314354}$
Received: December 1, 2009

Accepted after revision: March 14, 2010

Published online: May 12, 2010

\title{
Vegetative State and Minimally Conscious State: A Review of the Therapeutic Interventions
}

\author{
Miltiadis Georgiopoulos ${ }^{\mathrm{a}}$ Paraskevi Katsakiori ${ }^{\mathrm{a}}$ Zinovia Kefalopoulou $^{\mathrm{a}}$ \\ John Ellul $^{\text {b Elisabeth Chroni }}{ }^{\text {b }}$ Constantine Constantoyannis $^{\text {a }}$ \\ ${ }^{a}$ Functional Neurosurgery Unit, Department of Neurosurgery, and bepartment of Neurology, \\ Medical School of Patras, Patras, Greece
}

\section{Key Words}

Vegetative state $\cdot$ Minimally conscious state $\cdot$

Consciousness $\cdot$ Treatment outcome

\begin{abstract}
Background/Aims: The purpose of the present article is a systematic review of the proposed medical or surgical treatments in patients in chronic vegetative state (VS) or minimally conscious state (MCS), as well as of their mechanisms of action and limitations. Methods: For this review, we have agreed to include patients in VS or MCS having persisted for over 6 months in posttraumatic cases, and over 3 months in nontraumatic cases, before the time of intervention. Searches were independently conducted by 2 investigators between May 2009 and September 2009 in the following databases: Medline, Web of Science and the Cochrane Library. The electronic search was complemented by cross-checking the references of all relevant articles. Overall, 16 papers were eligible for this systematic review. Results: According to the 16 eligible studies, medical management by dopaminergic agents (levodopa, amantadine), zolpidem and median nerve stimulation, or surgical management by deep brain stimulation, extradural cortical stimulation, spinal cord stimulation and intrathecal baclofen have shown to improve the level of consciousness in certain cases. Conclusion: The treatments proposed for disorders of consciousness have not yet gained
\end{abstract}

the level of 'evidence-based treatments'; moreover, the studies to date have led to inconclusiveness. The published therapeutic responses must be substantiated by further clinical studies of sound methodology.

Copyright $\odot 2010$ S. Karger AG, Basel

\section{Introduction}

Progress in emergency treatment is responsible for the recovery of many patients daily who would have died otherwise. However, as a result, the number of patients in a vegetative state (VS) and in a minimally conscious state (MCS) has increased. The Multi-Society Task Force on Persistent VS defined VS as a pathologic condition of complete unawareness of the self and the environment, accompanied by sleep-wake cycles, with preservation of brainstem autonomic and hypothalamic function $[1,2]$. It was not until 2002 when Giacino et al. [3] published the definition and diagnostic criteria for the MCS. The MCS is characterized by inconsistent, but clearly discernible, behavioral evidence of consciousness. The VS and MCS are also called disorders of consciousness (DOC).

The causes of DOC are numerous and include traumatic brain injury, hypoxic damage, cerebrovascular ischemic or hemorrhagic injury, infection of the central nervous system, toxins, poisoning, degenerative diseases,

\section{KARGER}

Fax +41613061234 E-Mail karger@karger.ch www.karger.com
(C) 2010 S. Karger AG, Basel

1011-6125/10/0884-0199\$26.00/0

Accessible online at:

www.karger.com/sfn
Constantine Constantoyannis, Assistant Professor

Functional Neurosurgery Unit, Department of Neurosurgery

Medical School of Patras

GR-26500 Patras (Greece)

Tel. +30 261099 9495, Fax +30 261099 2997, E-Mail cconst@ med.upatras.gr 
tumors as well as congenital or developmental disorders [1-4]. When an acquired brain injury results in DOC, coma is the initial clinical manifestation [5]. Coma is defined as a state of complete unconsciousness from which the patient cannot be aroused; usually, it evolves within $2-4$ weeks into either a conscious state or VS $[1,5]$. The VS is considered as either a transitional state from coma to higher levels of consciousness or, if it persists for at least 1 month, as a so-called 'persistent' VS [6, 7]. VS that persists, according to international guidelines, for over 12 months after a traumatic brain injury, and for over 3 months after nontraumatic causes according to guidelines from the USA or 6 months according to guidelines from the UK, is considered a 'permanent' VS $[1,2,4]$. The prognosis of VS varies according to the cause. For instance, the prognosis is poor in adult patients with posttraumatic VS and poorer in those with nontraumatic etiologies [2]. The Multi-Society Task Force on Persistent VS reported that among patients who had been in VS after traumatic brain injury, 33\% recovered within the first 3 months, $13 \%$ between 3-6 months, and 6\% between $6-12$ months [2]. It is clear that DOC constitute a handicap for the patient, a continuous struggle for their families and a major medical and social challenge.

Arbitrarily, patients with DOC could be subdivided into 2 groups according to whether the predominant central nervous system damage is global or multifocal. A more diffuse type of damage is usually due to global ischemia and anoxia, in contrast to trauma or stroke, both of which may produce multifocal brain damage [8]. Although neuropathologic and neuroradiologic studies have revealed common structural abnormalities including diffuse axonal injury and damage to the dorsolateral part of the rostral brainstem and the thalamus $[9,10]$, the pathophysiology of VS and MCS varies from case to case and still, in most instances, remains unknown [11].

The purpose of the present manuscript is a systematic review of the proposed medical or surgical treatments of patients with chronic DOC. The mechanisms of action and limitations of the treatments will be discussed.

\section{Methods}

\section{Data Sources}

Searches were independently performed by 2 investigators between May 2009 and September 2009 in the following databases: Medline, Web of Science and the Cochrane Library. The following key words were used: 'vegetative state', 'minimally conscious', 'disorders of consciousness', 'effect', 'therapy', 'recovery', 'levodopa', 'amantadine', 'zolpidem', 'stimulation', 'baclofen', 'ethical' and 'ethics', in combination with the delimiters 'English language' and 'Humans' in the Medline database, and 'English language' in the Web of Science database. The above databases and key words were chosen in a consensus meeting. The electronic search was complemented by cross-checking the references of all relevant articles.

\section{Selection Criteria}

We have defined the inclusion and exclusion criteria during a consensus meeting. For this review, we agreed to include: (1) patients with a diagnosis of either VS or MCS; (2) patients with a duration of the condition of over 6 months in posttraumatic cases, and of over 3 months in nontraumatic cases, and (3) studies with any type of: methodological design, therapeutic management or assessments of outcome. Thus, patients in VS or MCS for whom the disease duration was less than the aforementioned duration were excluded. Cases in which the duration of the disease could not be determined were also excluded from the analysis.

The criterion of DOC duration was set in order to exclude cases of spontaneous recovery that could occur during the acute stages. The agreement was based on observations indicating that spontaneous recoveries during our time window occur only in $6 \%$ of the patients with posttraumatic DOC and in almost none of the patients with nontraumatic DOC $[1,2]$. The great diversity in methodology in a relatively small number of published studies led us to agree on the third criterion. Special attention was paid to identify the patients which have been described in more than 1 publication to avoid duplications.

\section{Results}

Overall, 16 of the 5,852 published papers $(4,806$ in Medline, 965 in the Web of Science, and 81 in the Cochrane Library) were found to satisfy the inclusion criteria for this systematic review of the literature. The small number of patients described in the chronic stages of DOC, the heterogeneity of the treatments evaluated, and the outcomes assessed precluded the use of pooled analyses. The characteristics of the described medical and surgical interventions are summarized in tables 1 and 2, respectively.

\section{Medical Interventions \\ Dopaminergic Agents \\ Clinical improvement after administration of levodo-} pa was documented in 4 patients altogether; 3 patients were in VS and 1 in MCS, and all after traumatic brain injury with disease durations of more than 6 months [11$14,27]$. As in these patients levodopa was administered for relief of rigidity and spasticity, not only were the parkinsonian symptoms reduced, but the patients also recovered from the DOC within 4 days to 1.5 months. The authors defined recovery as the patient's ability to com- 
Table 1. Pharmacological agents used in VS and MCS

\begin{tabular}{|c|c|c|c|c|c|}
\hline & Study & $\begin{array}{l}\text { Diagnosis } \\
\text { and number } \\
\text { of patients }\end{array}$ & $\begin{array}{l}\text { Type of brain } \\
\text { injury }\end{array}$ & $\begin{array}{l}\text { Disease } \\
\text { duration }\end{array}$ & $\begin{array}{l}\text { Improvement } \\
\text { and response } \\
\text { incidence rate }\end{array}$ \\
\hline \multirow[t]{3}{*}{ Levodopa } & Matsuda et al. [12] & $\mathrm{VS}, \mathrm{n}=2$ & traumatic & 7 and 12 months & yes - unknown \\
\hline & Haig and Ruess [13] & $\mathrm{VS}, \mathrm{n}=1$ & traumatic & 6 months & yes - unknown \\
\hline & Koeda and Takeshita [14] & MCS, $\mathrm{n}=1$ & traumatic & 22 months & yes - unknown \\
\hline \multirow[t]{2}{*}{ Amantadine } & Horiguchi et al. [15] & $\mathrm{VS}, \mathrm{n}=1$ & olivopontocerebellar & 3 years & yes - unknown \\
\hline & Schnakers et al. [16] & MCS, $\mathrm{n}=1$ & anoxic & $>2$ years & yes - unknown \\
\hline \multirow[t]{6}{*}{ Zolpidem } & Clauss and Nel [17] & $\mathrm{VS}, \mathrm{n}=3$ & $\begin{array}{l}\text { traumatic }(\mathrm{n}=2) \\
\text { anoxic }(\mathrm{n}=1)\end{array}$ & $3-5$ years & yes - unknown \\
\hline & Shames and Ring [18] & MCS, $\mathrm{n}=1$ & anoxic & 18 months & yes - unknown \\
\hline & Brefel-Courbon et al. [19] & MCS?, $\mathrm{n}=1$ & anoxic & 2 years & yes - unknown \\
\hline & Cohen and Duong [20] & MCS?, n =1 & anoxic & 8 months & yes - unknown \\
\hline & Whyte and Myers [21] & $\begin{array}{l}\text { VS, } \mathrm{n}=11 \text { and } \\
\text { MCS, } \mathrm{n}=3\end{array}$ & $\begin{array}{l}\text { traumatic }(\mathrm{n}=8) \\
\text { anoxic }(\mathrm{n}=5) \\
\text { stroke }(\mathrm{n}=1)\end{array}$ & $\begin{array}{l}\text { trauma: } 7-278 \text { months } \\
\text { other: } 3-49 \text { months }\end{array}$ & yes $-1 / 14$ \\
\hline & Singh et al. [22] & MCS, $\mathrm{n}=1$ & traumatic & 4 years & no \\
\hline $\begin{array}{l}\text { Median nerve } \\
\text { stimulation }\end{array}$ & Cooper et al. [23] & $\mathrm{VS}, \mathrm{n}=1$ & anoxic & 6 months & yes - unknown \\
\hline
\end{tabular}

Table 2. Surgical methods used in VS and MCS

\begin{tabular}{|c|c|c|c|c|c|c|}
\hline & Study & Type of study & $\begin{array}{l}\text { Diagnosis } \\
\text { and number } \\
\text { of patients }\end{array}$ & $\begin{array}{l}\text { Type of } \\
\text { brain injury }\end{array}$ & Disease duration & $\begin{array}{l}\text { Improvement } \\
\text { and response } \\
\text { incidence rate }\end{array}$ \\
\hline Deep brain stimulation & Schiff et al. [24] & case study & MCS, $\mathrm{n}=1$ & traumatic & 6 years & yes \\
\hline Extradural cortical stimulation & Canavero et al. [25] & case study & $\mathrm{VS}, \mathrm{n}=1$ & traumatic & 20 months & yes - unknown \\
\hline Spinal cord stimulation & Kanno et al. [8] & $\begin{array}{l}\text { prospective, uncontrolled, } \\
\text { nonrandomized } \\
\text { observational study }\end{array}$ & VS, $\mathrm{n}=214$ & $\begin{array}{l}\text { traumatic: } 106 \\
\text { anoxic: } 50 \\
\text { stroke: } 45\end{array}$ & $\begin{array}{l}\text { trauma: over } 1 \text { year } \\
\text { other: over } 3 \text { months }\end{array}$ & $\begin{array}{l}\text { yes - } \\
109 / 201(54 \%)\end{array}$ \\
\hline Intrathecal baclofen & Sara et al. [26] & case series & VS, $n=5$ & $\begin{array}{l}\text { traumatic: } 2 \\
\text { anoxic: } 1 \\
\text { hemorrhage: } 2\end{array}$ & $\begin{array}{l}\text { trauma: } 7-12 \text { months } \\
\text { other: } 6-11 \text { months }\end{array}$ & yes - unknown \\
\hline
\end{tabular}

municate, to obey correctly simple verbal commands and to use objects functionally $[3,11]$. Furthermore, 2 of the 4 patients exhibited a response in the form of electroencephalographic activity (EEG), i.e. alpha activity tended to replace delta or theta wave activity. The starting dose of levodopa was $450 \mathrm{mg}$ per day in the adult patients and $50 \mathrm{mg}(2 \mathrm{mg} / \mathrm{kg})$ per day in the pediatric patient [11].

In 1990, Horiguchi et al. [15] presented 1 patient who had been in VS for 3 years due to olivopontocerebellar atrophy and had recovered after administration of amantadine. Recently, cognitive and motor improvements by the administration of amantadine have been reproduced in 1 patient in chronic ( $>2$ years) postanoxic MCS [16]. In this case, a validated behavioral assessment scale (Coma Recovery Scale-Revised), actigraphy and consecutive positron emission tomography (PET) scans were carried out [28]. Throughout the observational period, the patient remained free of other centrally acting drugs. During treatment, the patient showed: (1) reproducible movements following commands and consistent automatic motor responses, (2) a significant improvement in limb movements recorded by actigraphy, and (3) a statistically 
significant $(\mathrm{p}<0.001)$ increase in amantadine-related metabolic activity by PET (approaching the normal range) of the dorsolateral prefrontal, temporoparietal and mesiofrontal cortices, bilaterally, and in the right-sided sensorimotor areas. In contrast, a withdrawal of amantadine resulted in a reduction in motor activity, while its reintroduction induced a significant increase in actigraphic activity.

\section{Zolpidem}

Clauss and Nel [17] presented 3 patients in VS who showed a clinical improvement after the use of zolpidem (10 mg/day). The VS was due to traumatic injury in 2 cases and due to anoxic damage in 1 and the duration of the disease was 3-5 years. Functional outcome was assessed using the Glasgow Coma Scale and the Rancho Los Amigos Scale. The improvement was transient, reflecting the drug's short half-life $(2.4 \mathrm{~h})$, but it was reproducible after administration of the same dose, and absent again when the drug's action faded [17]. The long-term efficacy of zolpidem was monitored for the whole period of observation (3-6 years) without tolerance; long-term side effects were not observed [17].

Similar clinical improvements without remarkable side effects were reproduced in another 3 studies after daily administration of 5-10 $\mathrm{mg}$ of zolpidem in a total of 3 patients suffering from postanoxic DOC (disease duration: 8-24 months) [18-20]. Of these studies, the work by Brefel-Courbon et al. [19] was of special interest as it evaluated zolpidem in a randomized, double-blind, placebo-controlled, single-patient trial. Zolpidem was administered to a 48 -year-old woman who had been suffering from akinetic mutism for over 2 years. Marked improvement was noted in motor performance and neuropsychological tests, as well as in the cerebral metabolism of the postrolandic territories and frontal cortex according to ${ }^{18} \mathrm{~F}$-fluorodeoxyglucose PET, and of the anterior cingulate and orbitofrontal cortices according to $\mathrm{H}_{2}{ }^{15} \mathrm{O}$ PET.

Contrary to the previously described positive effects of zolpidem, Whyte and Myers [21] have recently reported that in their double-blind, placebo-controlled, crossover design study on zolpidem (10 mg/day) and placebo, only 1 patient exhibited a clinically significant improvement, out of 14 patients who had been in either VS $(n=11)$ or $\operatorname{MCS}(n=3)$ due to trauma $(n=8)$, anoxia $(n=5)$ or stroke $(\mathrm{n}=1)$. That single patient reproducibly improved from VS to MCS; in the remaining 13 patients, not even a subclinical response was observed, indicating a bimodal type of response rather than a scaled one. The participants were assessed by the investigators using the Coma Recovery Scale-Revised [28]. However, during this trial, all patients had received some kind of psychoactive medication. Similarly, Singh et al. [22] did not confirm a therapeutic impact of zolpidem on a 44 -year-old man in posttraumatic MCS (disease duration: 4 years).

\section{Median Nerve Stimulation}

Median nerve stimulation has been tested in 1 patient only, who satisfied our inclusion criteria [23]. The patient, who had been in postanoxic VS for 6 months, received right median nerve stimulation (proposed pattern: asymmetric biphasic pulses; amplitude: 15-20 mA; frequency: $40 \mathrm{~Hz}$; pulse width: $300 \mu \mathrm{s}$, for $20 \mathrm{~s} / \mathrm{min}, 8-12 \mathrm{~h} /$ day). Positive responses were recorded, including better posture, visual pursuit and fixation, swallowing and phonation, within the first 3 months of treatment. No major complications were encountered.

\section{Surgical Interventions}

Deep Brain Stimulation

In a 6-month, double-blind, alternating crossover study, Schiff et al. [24] showed that bilateral deep brain stimulation (DBS) of the anterior intralaminar nuclei (central thalamus, CT) can induce behavioral responsiveness in a patient who had remained in MCS for 6 years before the intervention due to a traumatic brain injury. The frequency of specific, cognitively mediated behaviors according to the Coma Recovery Scale-Revised (motor, communication and arousal subscales) was increased while 'on' DBS compared with being 'off' DBS [24, 28]. Purposeful upper extremity limb movement and oral feeding had also improved in similar experimental conditions. No major complications were reported in this case.

Extradural Cortical Stimulation

Recently, Canavero et al. [25] have demonstrated that unilateral, bifocal, extradural cortical stimulation (ECS) could produce a therapeutic result in a patient who had been in posttraumatic VS for a period of 20 months. The investigators chose to stimulate the sulcus (parameters: 8-10 Hz, $65 \mu \mathrm{s}, 11 \mathrm{~mA}$ ) between the left parietal gyri P1 and P2 and the middle frontal sulcus (F2), including the dorsolateral prefrontal cortex (Brodmann's areas 8 and 46). A significant clinical response was described using the Coma Recovery Scale-Revised and the Levels of Cognitive Functioning scale $[28,29]$. The achieved improvement declined after the discontinuation of the stimulation but was regained after having restarted it. According 
to the authors, ECS is a minimally invasive and safe surgical procedure [25, 30, 31].

\section{Spinal Cord Stimulation}

The effects of spinal cord stimulation (SCS) on 214 patients who had been in VS due to trauma, anoxia or stroke were studied in a prospective observational study for 20 consecutive years (1986-2005) [8]. The SCS device was implanted into the epidural space between $\mathrm{C} 2$ and $\mathrm{C} 4$, stimulating the spinal cord in a cyclic mode of $15 \mathrm{~min}$ on and 15 min off only during daytime, without reaching the motor threshold (amplitude: 2.0-3.0 V; frequency: $70 \mathrm{~Hz}$; pulse width: $120 \mu \mathrm{s})$. At the beginning of the observation, the duration of the VS had been at least 1 year in traumatic cases and at least 3 months in nontraumatic cases. A clinical response was recorded in 109 of the $201 \mathrm{pa}-$ tients (54\%; 13 were lost to follow-up), and it was correlated with age below 35, traumatic brain injury and regional cerebral blood flow over $20 \mathrm{ml} / 100 \mathrm{~g} / \mathrm{min}$.

\section{Intrathecal Baclofen}

Sara et al. [26] reported that 5 patients in VS due to trauma $(n=2)$, hemorrhage $(n=2)$ and anoxia $(n=1)$ who had being receiving treatment with intrathecal baclofen (ITB) for spasticity improved their level of consciousness. The arousal level, the respective subscales of the Coma Recovery Scale-Revised and commands, not hindered by spasticity, were improved while the patients were free of sedative or other drugs for spasticity.

\section{Discussion}

The effects of a variety of medical and surgical treatments have been described or tested in a small number of patients by haphazard methodological designs. The lack of cohort or double-blind placebo-controlled studies, the heterogeneity of the patients' characteristics, the lack of properly defined inclusion and exclusion criteria, using ill-defined recovery criteria or not using standardized assessment tests are some of the reasons for the inconclusiveness. Furthermore, the number of patients who did not respond to interventions was not reported. Thus, the support for a specific treatment is limited at this stage.

Historical information about similar therapeutic results, often discovered accidentally, is available for almost all of the aforementioned treatments. For instance, positive effects of levodopa on the level of consciousness were observed by Higashi et al. [32] in 1977. Also, DBS for DOC has a long and interesting history [33].

Therapeutic Interventions in Chronic DOC
The first attempts to restore arousal and consciousness by activation of potentially recruitable cerebral networks via DBS were reported as long ago as in 1968 by McLardy et al. [34], in 1969 by Hassler et al. [35, 36] and in 1979 by Sturm et al. [37]. Hassler, the neurologist and neuroanatomist who wrote the anatomy of the thalamus for the Schaltenbrand stereotactic atlas, decided to stimulate the pallidum and the lateropolar nucleus of the contralateral thalamus [35, 36]. Sturm et al. [37], in their case study, chose the left thalamic reticular nucleus. Two more studies followed in the late 1980s, by neurosurgeons in Japan (Tsubokawa et al. [38]) and France (Cohadon and Richer [39]). In those studies, the targets were the thalamic center median-parafascicular complex and the mesencephalic reticular formation $[38,39]$.

In certain cases of the aforementioned studies investigating DBS for DOC, arousal responses were observed immediately at the onset of stimulation periods, and various improvements in the level of consciousness and functionality were recorded progressively during the postoperative period. Nevertheless, the short disease duration (within the known time frames for spontaneous recovery), the insufficient methodological and statistical analysis, not using any valid behavioral scale to assess clinical progression, the variance in the causes, and the old and probably inappropriate electrophysiological tests (e.g. auditory brainstem response and somatosensory evoked potentials) may be significant confounding factors in the evaluation of the treatment outcome in those patients operated in VS or MCS.

Recent attempts to improve the level of consciousness of patients in the acute stages of DOC have not been included in this review because sound judgment on their effectiveness cannot be made without large randomized trials and is precluded by the high proportion of spontaneous recoveries. Furthermore, these studies are also set back from the methodological issues discussed here. Nonetheless, the information derived from these studies may be useful for hypothesis generation and further testing. In fact, almost all treatments reported in our review have been tested on patients with DOC of short duration.

\section{Mechanisms of Action and Limitations of Medical Interventions}

It has been hypothesized that levodopa can work as a trigger agent to interrupt the vicious circle of exhaustion of neurotransmitters [11]. This hypothesis was based on the case of 1 patient whose level of consciousness was improved after receiving levodopa and maintained after discontinuation of the treatment [11]. It has also been 
suggested that the effectiveness of levodopa is probably dependent upon a confirmed diagnosis of VS or MCS, concomitant symptoms of parkinsonism and imaging findings of high-intensity lesions on the dopaminergic pathway by $\mathrm{T}_{2}$-weighted MRI [11]. Moreover, it has been suggested that an ineffectiveness of levodopa does not predict the ineffectiveness of other dopaminergic agents because of different mechanisms of action and the variability in damage locations on the dopaminergic pathways [11]. Of note, in 1 of the patients reported by Matsuda et al. [12], a DBS system was implanted in the left thalamus 6 months after the trauma, but no improvement was observed either then or in the following 6 months.

Amantadine, a dopaminergic agent initially developed as an antiinfluenza drug, acts both pre- and postsynaptically through an increase in dopamine release and through postsynaptic facilitation [40]

Zolpidem is a nonbenzodiazepine, $\omega_{1}$-specific, indirect GABA agonist that is used for insomnia. The $\alpha$-subunit, known also as the benzodiazepine or $\omega$-receptor, is the major modulating site of the GABA receptor [17]. According to Clauss and $\mathrm{Nel}[17,41]$, the mechanism of zolpidem's action in patients with DOC is based on the reactivation of dormant neural networks in the brain and on the reversal of diaschisis, which is a phenomenon displaying an absence of cooperation and integration of different neural networks of the brain. Brain injury and anoxia induce a neuroprotective increase in GABA receptor stimulation in order to suppress brain activity. Normally, this should be reversed in postacute changes. However, it seems that in some patients neurodormancy persists, affecting large or important areas of the brain. A normalization of regional cerebral blood flow (e.g. in frontal regions bilaterally), reversal of diaschisis (e.g. left-sided cerebellar diaschisis), and prevention of zolpidem's action by flumazenil has been shown in single-photon emission computed tomography studies in both baboons and humans who had been taking zolpidem [17, 42-44]. BrefelCourbon et al. [19] also hypothesized that zolpidem may activate limbic loops modulating motivational processes. This is based on the observation that GABA receptor stimulation could interact with limbic loops modulating subcortical pathways (globus pallidus and substantia nigra), then leading to disinhibition and thalamocortical overactivity. To explain the lack of efficacy, Singh et al. [22] noted that if the reversal of neurodormancy is important in VS, individuals at higher levels of consciousness, such as in MCS, may not benefit. Whyte and Myers [21] believe that administration of zolpidem for screening purposes is justified as the drug is inexpensive and of very low toxicity.

The right median nerve, according to Cooper et al. [23], can serve as a peripheral portal to the central nervous system because the spinoreticular component of the median nerve pathway synapses with neurons of the ascending reticular activating system. Putative mechanisms of action include increased cerebral blood flow, raised levels of dopamine and norepinephrine, and activation of Broca's area. The supporters of median nerve stimulation stress that therapy has to be initiated early because brain atrophy is in progress and it may be too late to achieve a recovery of brain function at a later stage [23]. It is suggested that some months or even years are needed in the chronic DOC [23].

\section{Mechanisms of Action and Limitations of Surgical Interventions}

The well-designed study by Schiff et al. [24] fueled new interest in the effects of DBS on the level of consciousness of patients in MCS. The authors provided evidence of reproducible and sustained improvement as well as of more enduring and slowly accumulating effects of DBS. It seems that the biological mechanisms in DBS work on 2 different time scales, 1 acute and 1 chronic, possibly via synaptic plasticity, normal learning and memory processes, and structural alterations [45]. DBS seems to increase the overall level of background synaptic activity, and thus the improvement may be further potentiated by pharmacologic agents in spite of the fact that they may not have been proved effective when used alone [45]. However, Schiff [45] suggested that only patients with some preserved large-scale integrative cerebral networks, identified by neurophysiologic or neuroradiologic tests, should be chosen for treatment. Chronically underactivated potentially recruitable networks and a partly deafferented and underactive CT characterize patients in MCS, in contrast to the patients in VS, who have widely disconnected and damaged thalamic and cortical neurons $[45,46]$. Several imaging studies have demonstrated the preservation of large-scale functional cerebral networks in MCS patients [47-51].

Schiff and various colleagues have proposed a framework for the use of DBS in MCS and the choice of the CT, specifically the thalamic anterior intralaminar nuclei, as a target with unique properties [24, 45, 46, 52, 53]. Firstly, the CT is vulnerable to disconnection and dysfunction after brain injuries such as trauma, anoxia and hypoxiaischemia, leading to a global downregulation of the cerebral metabolism [45]. Furthermore, the CT plays an in- 
termediate key role in forebrain arousal, receiving ascending connections from the brainstem and basal forebrain 'arousal systems', and descending connections from the mesial frontal cortex [54], and its neurons' activity grades depending on the level of arousal [45]. Besides, intralaminar nuclei participate in the integration of longrange corticocortical and corticostriatopallidal-thalamocortical networks. DBS of the CT is primarily expected to depolarize neurons of the cortex and striatum. Extensive anatomic, neurophysiologic and neuroradiologic data render the CT possibly the only target that allows the stimulation of 1 area for simultaneous activation of wide corticocortical and striatal networks [45].

Limitations for future relevant clinical studies include the heterogeneity of patients' characteristics and of their brain injuries (location, distribution and duration). Unfortunately, a generalization of the results reported by Schiff et al. [24] is not possible until more studies will have evaluated the efficacy of DBS in DOC and provided an understanding of which patients might respond.

Canavero et al. [25] showed that ECS in the target areas can induce a clinical response in VS. The frontoparietal association areas are related to 'self'-consciousness and are some of the most commonly impaired networks in neuroradiologic studies of the VS $[25,55,56]$. The dorsolateral prefrontal cortex is connected with the supplementary motor area, possibly influencing motor improvement. In addition, it has been hypothesized that isolated thalamocortical circuits are recruited and resynchronized [25, 30].

Kanno et al. [8] has recently shown that SCS, or dorsal column stimulation, a surgical technique mostly applied in chronic pain, could be effective in VS. According to the investigators, cervical SCS increases the regional cerebral blood flow via brainstem pathways, increases the levels of neurotransmitters and neuromodulators, and enhances $\alpha_{1}$ sympathetic activity, promoting neuroplasticity in the central nervous system [8]. Also, stimulation of the undamaged nonspecific pathways activates residual functional cortical areas [8].

Baclofen is a $\mathrm{GABA}_{\mathrm{B}}$ receptor agonist and one of the most widely used oral antispastic medications [57]. ITB administration, usually via implantable drug delivery pumps, is an established treatment for severe spasticity.

There are various hypotheses on the putative effect of ITB. Sara et al. [26] have proposed that baclofen could modulate spinal cord segmental activities and the centripetal neuronal outputs reaching the cortex or the dysregulated sleep-wake cycles interfering with consciousness. It is also assumed that a direct pharmacologic effect on the brain does not seem to be possible since intrathecal administration leads to plasma levels of baclofen at or below the limit of quantification [58]. On the other hand, Taira and Hori [59] speculated that baclofen might hasten the repair of diffuse axonal injury because baclofen improves nerve conduction in demyelinated axons. ITB involves the spinal GABAergic system like SCS, which - as mentioned above - has been used in VS with positive results $[8]$.

\section{Conclusions}

The effects of a variety of medical and surgical treatments have been described or tested on a small number of patients in VS or MCS by haphazard methodological designs. The treatments proposed for DOC have not yet gained the level of evidence-based treatment; moreover, the studies to date have led to inconclusiveness $[8,60]$. According to the 16 studies analyzed in the present review, medical management by dopaminergic agents (levodopa and amantadine), zolpidem and median nerve stimulation, or surgical management by DBS, ECS, SCS and ITB have shown to improve the level of consciousness in certain cases. However, this needs to be established by further clinical studies of sound methodology, e.g. prospective cohort studies or double-blind placebo-controlled studies. The mechanisms of action and limitations of the suggested treatments should be further investigated.

\section{Acknowledgment}

This study was funded by the University of Patras Research Committee (K. Karatheodori Program).

References

Multi-Society Task Force on PVS: Medical
aspects of the persistent vegetative state. Part
1. N Engl J Med 1994;330:1499-1508.
2 Multi-Society Task Force on PVS: Medical
aspects of the persistent vegetative state. Part
2. N Engl J Med 1994;330:1572-1579.
3 Giacino JT, Ashwal S, Childs N, Cranford R,
Jennett B, Katz DI, Kelly JP, Rosenberg JH,
Whyte J, Zafonte RD, Zasler ND: The mini-
mally conscious state: definition and diag-
nostic criteria. Neurology 2002;58:349-353.
4 The vegetative state: guidance on diagnosis
and management. Clin Med 2003;3:249-254.
5 Plum F, Posner JB: The Diagnosis of Stupor
and Coma, ed 3. Philadelphia, Davis, 1980.

Stereotact Funct Neurosurg 2010;88:199-207 
6 Giacino JT, Trott CT: Rehabilitative management of patients with disorders of consciousness: grand rounds. J Head Trauma Rehabil 2004;19:254-265.

7 Zeman A: What is consciousness and what does it mean for the persistent vegetative state? Adv Clin Neurosci Rehabil 2003;3:1214.

-8 Kanno T, Morita I, Yamaguchi S, Yokoyama T, Kamei Y, Anil SM, Karagiozov KL: Dorsal column stimulation in persistent vegetative state. Neuromodulation 2009;12:33-38.

$\checkmark 9$ Adams JH, Graham DI, Jennett B: The neuropathology of the vegetative state after an acute brain insult. Brain 2000;123:13271338.

-10 Kampfl A, Franz G, Aichner F, Pfausler B, Haring HP, Felber S, Luz G, Schocke M, Schmutzhard E: The persistent vegetative state after closed head injury: clinical and magnetic resonance imaging findings in 42 patients. J Neurosurg 1998;88:809-816.

11 Matsuda W, Komatsu Y, Yanaka K, Matsumura A: Levodopa treatment for patients in persistent vegetative or minimally conscious states. Neuropsychol Rehabil 2005;15: 414-427.

12 Matsuda W, Matsumura A, Komatsu Y, Yanaka K, Nose T: Awakenings from persistent vegetative state: report of three cases with parkinsonism and brain stem lesions on MRI. J Neurol Neurosurg Psychiatry 2003; 74:1571-1573.

13 Haig AJ, Ruess JM: Recovery from vegetative state of six months' duration associated with Sinemet (levodopa/carbidopa). Arch Phys Med Rehabil 1990;71:1081-1083.

14 Koeda T, Takeshita K: A case report of remarkable improvement of motor disturbances with L-DOPA in a patient with postdiffuse axonal injury. Brain Dev 1998;20: 124-126.

15 Horiguchi J, Inami Y, Shoda T: Effects of long-term amantadine treatment on clinical symptoms and EEG of a patient in a vegetative state. Clin Neuropharmacol 1990;13: 84-88.

16 Schnakers C, Hustinx R, Vandewalle G, Majerus S, Moonen G, Boly M, Vanhaudenhuyse A, Laureys S: Measuring the effect of amantadine in chronic anoxic minimally conscious state. J Neurol Neurosurg Psychiatry 2008;79:225-227.

17 Clauss R, Nel W: Drug-induced arousal from the permanent vegetative state. NeuroRehabilitation 2006;21:23-28.

18 Shames JL, Ring H: Transient reversal of anoxic brain injury-related minimally conscious state after zolpidem administration: a case report. Arch Phys Med Rehabil 2008;89: 386-388.

19 Brefel-Courbon C, Payoux P, Ory F, Sommet A, Slaoui T, Raboyeau G, Lemesle B, Puel M, Montastruc JL, Demonet JF, Cardebat D: Clinical and imaging evidence of zolpidem effect in hypoxic encephalopathy. Ann Neurol 2007;62:102-105.
20 Cohen SI, Duong TT: Increased arousal in a patient with anoxic brain injury after administration of zolpidem. Am J Phys Med Rehabil 2008;87:229-231.

21 Whyte J, Myers R: Incidence of clinically significant responses to zolpidem among patients with disorders of consciousness: a preliminary placebo controlled trial. Am J Phys Med Rehabil 2009;88:410-418.

22 Singh R, McDonald C, Dawson K, Lewis S, Pringle AM, Smith S, Pentland B: Zolpidem in a minimally conscious state. Brain Inj 2008;22:103-106.

23 Cooper EB, Scherder EJ, Cooper JB: Electrical treatment of reduced consciousness: experience with coma and Alzheimer's disease. Neuropsychol Rehabil 2005;15:389-405.

24 Schiff ND, Giacino JT, Kalmar K, Victor JD, Baker K, Gerber M, Fritz B, Eisenberg B, Biondi T, O’Connor J, Kobylarz EJ, Farris S, Machado A, McCagg C, Plum F, Fins JJ, Rezai AR: Behavioural improvements with thalamic stimulation after severe traumatic brain injury. Nature 2007;448:600-603.

25 Canavero S, Massa-Micon B, Cauda F, Montanaro E: Bifocal extradural cortical stimulation-induced recovery of consciousness in the permanent post-traumatic vegetative state. J Neurol 2009;256:834-836.

26 Sara M, Pistoia F, Mura E, Onorati P, Govoni $S$ : Intrathecal baclofen in patients with persistent vegetative state: 2 hypotheses. Arch Phys Med Rehabil 2009;90:1245-1249.

27 Matsuda W, Sugimoto K, Sato N, Watanabe T, Yanaka K, Matsumura A, Nose T: A case of primary brainstem injury recovered from persistent vegetative state after L-DOPA administration (in Japanese). No To Shinkei 1999;51:1071-1074.

28 Giacino JT, Kalmar K, Whyte J: The JFK Coma Recovery Scale-Revised: measurement characteristics and diagnostic utility. Arch Phys Med Rehabil 2004;85:2020-2029.

29 Hagan C, Malkmus D, Durham P: Levels of cognitive function; in Professional Staff Association (eds): Rehabilitation of the Head-Injured Adult. Comprehensive Physical Management. Downey, Rancho Los Amigos Hospital, 1979.

30 Canavero S: Textbook of therapeutic cortical stimulation. Hauppauge, Nova Science, 2009.

- 31 Canavero S, Bonicalzi V, Intonti S, Crasto S, Castellano G: Effects of bilateral extradural cortical stimulation for plegic stroke rehabilitation: case report. Neuromodulation 2006;9:28-33.

32 Higashi K, Sakata Y, Hatano M, Abiko S, Ihara K, Katayama S, Wakuta Y, Okamura T, Ueda H, Zenke M, Aoki H: Epidemiological studies on patients with a persistent vegetative state. J Neurol Neurosurg Psychiatry 1977;40:876-885.
33 Schiff ND: DBS disorders of consciousness; in Lozano AM, Gildenberg PL, Tasker RR (eds): Textbook of Stereotactic and Functional Neurosurgery, ed 2. Berlin, Springer, 2009, pp 2981-2990.

34 McLardy T, Ervin F, Mark V, Scoville W, Sweet W: Attempted inset-electrodes-arousal from traumatic coma: neuropathological findings. Trans Am Neurol Assoc 1968;93: 25-30.

35 Hassler R, Ore GD, Dieckmann G, Bricolo A, Dolce G: Behavioural and EEG arousal induced by stimulation of unspecific projection systems in a patient with post-traumatic apallic syndrome. Electroencephalogr Clin Neurophysiol 1969;27:306-310.

- 36 Hassler R, Ore GD, Bricolo A, Dieckmann G, Dolce G: EEG and clinical arousal induced by bilateral long-term stimulation of pallidal systems in traumatic vigil coma. Electroencephalogr Clin Neurophysiol 1969;27:689690.

37 Sturm V, Kühner A, Schmitt HP, Assmus H, Stock G: Chronic electrical stimulation of the thalamic-unspecific activating system in a patient with coma due to midbrain and upper brain stem infarction. Acta Neurochir (Wien) 1979;47:235-244.

- 38 Tsubokawa T, Yamamoto T, Katayama Y, Hirayama T, Maejima $S$, Moriya T: Deep-brain stimulation in a persistent vegetative state: follow-up results and criteria for selection of candidates. Brain Inj 1990;4:315-327.

39 Cohadon F, Richer E: Deep cerebral stimulation in patients with post-traumatic vegetative state: 25 cases (in French). Neurochirurgie 1993;39:281-292.

40 Zafonte RD, Watanabe T, Mann NR: Amantadine: a potential treatment for the minimally conscious state. Brain Inj 1998;12:617621

41 Clauss RP, Nel WH: Effect of zolpidem on brain injury and diaschisis as detected by $99 \mathrm{mTc}$ HMPAO brain SPECT in humans. Arzneimittelforschung 2004;54:641-646.

42 Clauss RP, Güldenpfennig WM, Nel HW, Sathekge MM, Venkannagari RR: Extraordinary arousal from semi-comatose state on zolpidem: a case report. S Afr Med J 2000;90: 68-72.

-43 Clauss RP, Dormehl IC, Kilian E, Louw WK, Nel WH, Oliver DW: Cerebral blood perfusion after treatment with zolpidem and flumazenil in the baboon. Arzneimittelforschung 2002;52:740-744.

44 Cohen L, Chaaban B, Habert MO: Transient improvement of aphasia with zolpidem. N Engl J Med 2004;350:949-950.

45 Schiff ND: Central thalamic deep-brain stimulation in the severely injured brain: rationale and proposed mechanisms of action. Ann NY Acad Sci 2009;1157:101-116.

46 Schiff ND, Fins JJ: Deep brain stimulation and cognition: moving from animal to patient. Curr Opin Neurol 2007;20:638-642. 
-47 Boly M, Faymonville ME, Peigneux P, Lambermont B, Damas P, del Fiore G, Degueldre C, Franck G, Luxen A, Lamy M, Moonen G, Maquet P, Laureys S: Auditory processing in severely brain-injured patients: differences between the minimally conscious state and the persistent vegetative state. Arch Neurol 2004;61:233-238.

48 Coleman MR, Rodd JM, Davis MH, Johnsrude IS, Menon DK, Pickard JD, Owen AM: Do vegetative patients retain aspects of language comprehension? Evidence from fMRI. Brain 2007; 130:2494-2507.

-49 Di HB, Yu SM, Weng XC, Laureys S, Yu D, Li JQ, Qin PM, Zhu YH, Zhang SZ, Chen YZ: Cerebral response to patient's own name in the vegetative and minimally conscious states. Neurology 2007;68:895-899.
50 Owen AM, Coleman MR, Boly M, Davis $\mathrm{MH}$, Laureys S, Pickard JD: Detecting awareness in the vegetative state. Science 2006;313: 1402 .

-51 Schiff ND, Rodriguez-Moreno D, Kamal A, Kim KH, Giacino JT, Plum F, Hirsch J: fMRI reveals large-scale network activation in minimally conscious patients. Neurology 2005;64:514-523.

52 Schiff ND, Plum F: The role of arousal and 'gating' systems in the neurology of impaired consciousness. J Clin Neurophysiol 2000;17: 438-452.

53 Shirvalkar P, Seth M, Schiff ND, Herrera DG: Cognitive enhancement with central thalamic electrical stimulation. Proc Nat Acad Sci USA 2006;103:17007-17012.

54 Krout KE, Belzer RE, Loewy AD: Brainstem projections to midline and intralaminar thalamic nuclei of the rat. J Comp Neurol 2002; 448:53-101.

55 Baars BJ, Ramsoy TZ, Laureys S: Brain, conscious experience and the observing self. Trends Neurosci 2003;26:671-675.
56 Laureys S: The neural correlate of (un)awareness: lessons from the vegetative state. Trends Cogn Sci 2005;9:556-559.

57 Richard I, Menei P: Intrathecal baclofen in the treatment of spasticity, dystonia and vegetative disorders. Acta Neurochir Suppl 2007;97:213-218.

58 Sara M, Sacco S, Cipolla F, Onorati P, Scoppetta C, Albertini G, Carolei A: An unexpected recovery from permanent vegetative state. Brain Inj 2007;21:101-103.

59 Taira T, Hori T: Intrathecal baclofen in the treatment of post-stroke central pain, dystonia, and persistent vegetative state. Acta Neurochir Suppl 2007;97:227-229.

60 Lombardi F, Taricco M, de Tanti A, Telaro E, Liberati A: Sensory stimulation of brain-injured individuals in coma or vegetative state: results of a Cochrane systematic review. Clin Rehabil 2002;16:464-472. 